\title{
GAMBARAN TINGKAT PENGETAHUAN PASIEN PENDERITA KOLESTEROL TINGGI TENTANG ATURAN PAKAI OBAT ALLOPURINOL DI KLINIK INGGIT MEDICAL CENTRE MAKASSAR
}

\author{
Zulfiah $^{1}$ \\ Jurusan Farmasi Politeknik Sandi Karsa ${ }^{1}$
}

\begin{abstract}
ABSTRAK
Asam urat biasanya diderita pria berusia 40 tahun ke atas dan wanita yang sudah menopause. Sebagian besar penderita asam urat juga memiliki penyakit lain seperti hipertensi, diabetes, penyakit ginjal. Dimana pendapat masyarakat bahwa ngilu sendi berarti asam urat, pengertian ini perlu diluruskan karena tidak semua keluhan dari nyeri sendi disebabkan oleh asam urat, untuk itu perlu dilakukan pemeriksaan laboratorium. Dimana penelitian ini bertujuan sebagai studi untuk mengetahui pengetahuan pasien tentang aturan pakai allopurinol di Klinik Inggit Medical Centre Makassar. Jenis penelitian ini adalah dengan menggunakan instrument penelitian berupa kuesioner yang dibagi kepada 34 responden yang datang berobat dan diberi resep allopurinol di Klinik Inggit Medical Centre Makassar. Dari hasil penelitian disimpulkan bahwa pengetahuan pasien tentang aturan pakai allopurinol sebesar 83,3\% dimana jumlah persen menunjukkan bahwa pasien yang datang berobat tahu mengenai aturan pakai allopurinol.
\end{abstract}

Kata kunci: Pengetahuan, Aturan Pakai, Allopurinol.

Corespondensi Author:

Zulfiah

piamuchtar@gmail.com 


\section{PENDAHULUAN}

\section{A. Latar Belakang}

Kesehatan adalah keadaan sejahtera dari badan, jiwa, dan sosial yang memungkinkan setiap orang hidup produktif secara sosial dan ekonomis. Atas dasar definisi kesehatan tersebut, maka manusia selalu dilihat sebagai satu kesatuan yang utuh dari unsur badan, jiwa, sosial, yang tidak dititik beratkan pada penyakit tetapi pada kualitas hidup yang terdiri dari kesejahteraan dan produktifitas sosial ekonomi (Justiadi, 2012).

Hiperurisemia adalah keadaan di mana terjadi peningkatan kadar asam urat (AU) darah di atas normal. Hiperurisemia bisa terjadi karena peningkatan metabolisme AU (overproduction), penurunan pengeluaran AU urin (underexcretion), atau gabungan keduanya. Keadaan hiperurisemia tidak selalu identik dengan artritis gout akut, artinya tidak selalu artritis gout disertai dengan peninggian asam urat (Noer, 1996). Hiperurisemia yang berkepanjangan dapat menyebabkan gout atau pirai, namun tidak semua hiperurisemia akan menimbulkan kelainan patologi berupa gout.

Secara umum penanganan berguna memberikan edukasi, pengaturan diet, istirahat sendi dan pengobatan. Pengobatan dilakukan sejak dini agar tidak terjadi kerusakan sendi ataupun komplikasi lain, misalnya pada ginjal. Obat penurun asam urat seperti allopurinol atau obat urikosurik tidak boleh diberikan pada stadium akut.

Namun pada pasien yang telah rutin mendapat obat penurun asam urat, sebaiknya tetap diberikan (Sudoyo, 2009).

Berdasarkan pengalaman, peneliti melihat sebagian masyarakat yang menderita gout yang mengkonsumsi allopurinol langsung meminum allopurinol untuk menghilangkan nyeri ketika mereka merasakan gejala asam uratnya meningkat baik itu pada siang hari atau kapan saja mereka ingin meminum obat, walaupun belum waktunya untuk meminum obat. Padahal aturan pakai allopurinol yang sebenarnya yaitu cukup diminum satu kali sehari saja pada malam hari. Hal ini yang membuat peneliti tertarik mengangkat judul "Gambaran Tingkat Pengetahuan Pasien Penderita Kolesterol Tinggi Tentang Aturan Pakai Obat Allopurinol Di Klinik Inggit Medical Centre Makassar" untuk melihat sejauh mana pengetahuan masyarakat penderita gout tentang aturan pakai allopurinol yang diresepkan oleh dokter.

Berdasarkan latar belakang diatas, sehingga dilakukan penelitian ini yakni untuk mengetahui pengetahuan pasien tentang aturan pakai allopurinol di Klinik Inggit Medical Centre Makassar.

\section{B. Rumusan Masalah}

Adapun rumusan masalah dalam penelitian ini adalah bagaimana pengetahuan pasien tentang aturan pakai allopurinol di Klinik Inggit Medical Centre Makassar?

\section{Tujuan Penelitian}

Tujuan penelitian ini adalah untuk mengetahui pengetahuan pasien tentang aturan pakai allopurinol di Klinik Inggit Medical Centre Makassar.

\section{Manfaat Penelitian}

Melalui penelitian ini dapat memperoleh informasi mengenai aturan pakai allopurinol yang tepat.

\section{METODE PENELITIAN}

\section{A. Jenis Penelitian}

Jenis penelitian ini adalah penelitian deskriptif menggunakan instrumen kuesioner, yang bertujuan untuk menggambarkan pengetahuan pasien tentang aturan pakai allopurinol, berdasarkan peresepan allopurinol di Klinik Inggit Medical Centre Makassar.

\section{B. Waktu Dan Tempat Penelitian}

Penelitian ini dilaksanakan di Klinik Inggit Medical Centre Makassar, pada tanggal bulan Oktober 2020.

\section{Populasi dan Sampel}

\section{Populasi}

Populasi dalam penelitian ini yaitu sebanyak 68 pasien yang diberikan resep obat allopurinol dari dokter mulai bulan Agustus September 2020 di Klinik Inggit Medical Centre Makassar.

2. Sampel

Sampel dalam penelitian ini yaitu sebanyak 34 pasien yang diberikan resep allopurinol dari dokter mulai pada bulan Agustus - September 2020 di Klinik Inggit Medical Centre Makassar.

Teknik penarikan sampel:

Teknik penarikan sampel dalam penelitian ini menggunakan rumus slovin:

$$
n=\frac{N}{\left(1+\mathrm{N} \cdot \mathrm{e}^{2}\right)}
$$

$\mathrm{n} \quad=$ jumlah sampel penelitian

$\mathrm{N}=$ jumlah populasi

$\mathrm{e}^{2}=$ persesi (ditetapkan $10 \%$ dengan tingkat kepercayaan 90\%)

$$
n=\frac{68}{\left(1+68.0,1^{2}\right)}
$$




$$
\begin{aligned}
& n=\frac{68}{1+68.0,01} \\
& n=\frac{68}{1+1} \\
& n=\frac{68}{2} \\
& n=34 \text { sampel }
\end{aligned}
$$

\section{Teknik Pengumpulan Dan Pengelolahan Data}

1. Pengumpulan data

a. Sumber data berupa data primer yang dikumpulkan dengan membagikan kuesioner kepada responden

b. Setiap pertanyaan dalam kuesioner disediakan dalam 4 (empat) pilihan jawaban yaitu sangat tahu, tahu, kurang tahu, dan tidak tahu.

a. Untuk jawaban sangat tahu, diberi nilai $=4$

b. Untuk jawaban tahu, diberi nilai $=3$

c. Untuk jawaban kurang tahu, diberi nilai $=2$

d. Untuk jawaban tidak tahu, diberi nilai $=1$

\section{Pengolahan data}

Data yang diperoleh kemudian diolah untuk menentukan persentase jawaban responden dengan menggunakan rumus:

$\%$ Skor perolehan $=$

$=\frac{\text { jumlah poin yang diperoleh }}{\text { skor ideal }} \times 100 \%$

Skor ideal $=$ Jumlah Responden X Jumlah Pertanyaan

Data hasil kuesioner tersebut selanjutnya di buat dalam bentuk tabel lalu ditentukan tingkat pengetahuan dan diberi nilai sebagai berikut:

1. Sangat Tahu: Jika \% jawaban responden $85 \%$ $-100 \%$

2. Tahu: Jika $\%$ jawaban responden $65 \%-84 \%$

3. Kurang Tahu: Jika $\%$ jawaban responden $45 \%$ $-64 \%$

4. Tidak Tahu: Jika \% jawaban responden $25 \%$ $44 \%$

\section{E. Analisis dan Penyajian Data}

1. Data yang diperoleh selanjutnya dianalisis untuk mengetahui sejauh mana pengetahuan aturan pakai dan penggunaan allopurinol di Klinik Inggit Medical Centre Makassar dan disajikan dalam bentuk tabel.

2. Data yang diperoleh diolah menggunakan Skala Likert, selanjutnya faktor yang mempengaruhi ditentukan berdasar kan pilihan jawaban responden.
1. Tingkat pengetahuan aturan pakai dan penggunaan obat adalah frekuensi jumlah obat allopurinol yang diresepkan di Klinik Inggit Medical Centre Makassar, dibagi dalam tiga kelompok yaitu tinggi, sedang, dan rendah dalam kurung waktu yang ditentukan.

2. Resep adalah permintaan tertulis dari seorang dokter kepada apoteker pengelola apotek untuk menyiapkan atau membuat, meracik, serta menyerahkan obat kepada pasien.

3. Allopurinol berguna untuk menurunkan kadar asam urat. Allopurinol kira-kira $80 \%$ diserap setelah pemakaian oral, allopurinol yang masa paruhnya pendek cukup diberikan satu kali sehari.

4. Klinik adalah fasilitas pelayanan kesehatan yang menyelenggarakan pelayanan medis dasar dan atau spesialistik.

\section{HASIL DAN PEMBAHASAN}

\section{A. Hasil Penelitian}

Berdasarkan hasil penelitian yang dilakukan terhadap 34 orang responden atau pasien yang diberikan resep allopurinol dari dokter di Klinik Inggit Medical Centre Makassar, pengumpulan data dimulai pada bulan Agustus September 2020 dengan total sampel 34 orang dan bersedia menjawab kuesioner. Alat pengumpulan data yang digunakan yaitu kuesioner, yang terdiri dari 9 pertanyaan. Kuesioner yang disusun mengenai Studi Pengetahuan Pasien tentang Aturan Pakai Allopurinol di Klinik Inggit Medical Centre Makassar.

Hasil data yang diperoleh selama penelitian di uraikan berdasarkan pertanyaan yang dapat dilihat pada tabel-tabel berikut:

1. Karakteristik Responden

Karakteristik responden berupa jenis kelamin, umur dan jenis pekerjaan responden yang dapat dilihat pada tabel-tabel berikut.

Table I. Karakteristik Responden Berdasarkan Jenis Kelamin

\begin{tabular}{cccc}
\hline No. & $\begin{array}{c}\text { Jenis } \\
\text { Kelamin }\end{array}$ & $\begin{array}{c}\text { Jumlah } \\
\text { (Responden) }\end{array}$ & $\begin{array}{c}\text { Persentase } \\
(\boldsymbol{\%})\end{array}$ \\
\hline 1. & Laki-laki & 16 & 47 \\
\hline 2. & Perempuan & 18 & 53 \\
\hline & Jumlah & 34 & 100 \\
\hline
\end{tabular}

Sumber : Data Primer 2020

Berdasarkan tabel diatas menunjukkan bahwa jumlah responden laki-laki 16 orang (47\%) dan perempuan 18 orang $(53 \%)$.

\section{F. Defenisi Operasional}


Tabel II. Karakteristik Responden Berdasarkan Umur

\begin{tabular}{cccc}
\hline No. & $\begin{array}{c}\text { Umur } \\
\text { (Tahun) }\end{array}$ & $\begin{array}{c}\text { Jumlah } \\
\text { (Responden) }\end{array}$ & $\begin{array}{c}\text { Persentase } \\
(\boldsymbol{\%})\end{array}$ \\
\hline 1 & $45-52$ & 6 & 18 \\
\hline 2 & $53-60$ & 9 & 26,5 \\
\hline 3 & $61-68$ & 9 & 26,5 \\
\hline 4 & $69-76$ & 10 & 29 \\
\hline \multicolumn{2}{c}{ Jumlah } & 34 & 100 \\
\hline
\end{tabular}

Sumber: Data Primer 2020

Berdasarkan tebel diatas diperoleh data umur responden mulai dari umur 45-52 tahun berjumlah 6 orang (18\%), umur 53-60 tahun berjumlah 9 orang (26,5\%), umur 61-68 tahun berjumlah 9 orang $(26,5 \%)$ dan umur $69-76$ tahun berjumlah 10 orang $(29 \%)$.

Tabel III. Karakteristik Responden Berdasarkan Jenis Pekerjaan

\begin{tabular}{cccc}
\hline No. & Pekerjaan & $\begin{array}{c}\text { Jumlah } \\
\text { (Responden) }\end{array}$ & $\begin{array}{c}\text { Persen } \\
(\%)\end{array}$ \\
\hline 1. & PNS & 6 & 18 \\
\hline 2. & $\begin{array}{c}\text { Pegawai } \\
\text { Swasta }\end{array}$ & 8 & 24 \\
\hline 3. & $\begin{array}{c}\text { Ibu Rumah } \\
\text { Tangga (IRT) }\end{array}$ & 11 & 32 \\
\hline 4. & DLL & 9 & 26 \\
\hline & Jumlah & 34 & 100 \\
\hline
\end{tabular}

Sumber: Data Primer 2020

Berdasarkan tabel diatas diperoleh data pekerjaan responden mulai dari PNS sebanyak 6 orang (18\%), pegawai spwasta sebanyak 8 orang $(24 \%)$, IRT sebanyak 11 orang (32\%), dan lain-lain sebanyak 9 orang $(26 \%)$.

\section{Hasil Jawaban Kuesioner}

Adapun hasil jawaban kuesioner responden tentang studi pengetahuan pasien tentang aturan pakai allopurinol di Klinik Inggit Medical Centre Makassar, dapat dilihat pada tabel berikut:

Tabel 4. Hasil Jawaban Responden Berdasarkan Pertanyaan Kuesioner
Berdasarkan tabel diatas menunjukkan bahwa, persentase skor jawaban responden sebesar 83,3\% termasuk kategori tahu. Hal ini berarti pasien yang datang berobat di Klinik Inggit Medical Centre Makassar tahu tentang aturan pakai allopurinol yang telah di resepkan oleh dokter.

\section{B. Pembahasan}

Asam urat ini biasanya diderita pria berusia 40 tahun ke atas dan wanita yang sudah menopause. Sebagian besar penderita asam urat juga memiliki penyakit lain seperti hipertensi, diabetes, penyakit ginjal, atau mengalami obesitas. Beberapa pendapat masyarakat bahwa ngilu sendi berarti asam urat, pengertian ini perlu diluruskan karena tidak semua keluhan dari nyeri sendi disebabkan oleh asam urat, untuk itu perlu dilakukan pemeriksaan laboratorium.

Gangguan metabolisme yang mendasarkan gout adalah hiperurisemia dimana kadar AU di atas $7 \mathrm{mg} / \mathrm{dl}$ pada laki-laki dan $6 \mathrm{mg} / \mathrm{dl}$ pada perempuan dipergunakan sebagai batasan hiperurisemia. Pengobatan dilakukan sejak dini agar tidak terjadi kerusakan sendi ataupun komplikasi lain, misalnya pada ginjal.

Penelitian ini bertujuan sebagai studi untuk mengetahui pengetahuan pasien tentang aturan pakai allopurinol mulai pada bulan Agustus September 2020 di Klinik Inggit Medical Centre Makassar. Dengan memberikan kuesioner kepada pasien yang datang berobat dan diberi resep allopurinol dari dokter yang berisikan pertanyaan-pertanyaan dan bersedia menjawab kuesioner.

Adapun hasil penelitian yang telah dilakukan menunjukkan bahwa persentase data pengetahuan pasien tentang aturan pakai allopurinol di Klinik Inggit Medical Centre Makassar sebesar 83,3\% (Tabel IV) termasuk kategori tahu, dimana jumlah persen menunjukkan bahwa pasien yang datang berobat tahu mengenai aturan pakai allopurinol. Hal ini

\begin{tabular}{|c|c|c|c|c|c|c|c|c|c|c|}
\hline \multirow[t]{2}{*}{ No } & \multirow[t]{2}{*}{ Soal } & \multicolumn{2}{|c|}{ Sangat Tahu } & \multicolumn{2}{|c|}{ Tahu } & \multicolumn{2}{|c|}{ Kurang tahu } & \multicolumn{2}{|c|}{ Tidak tahu } & \multirow{3}{*}{$\begin{array}{l}\text { Jumlatipengaruhi dari bebagai faktor, diantaranya } \\
\text { Jawab pasien memperoleh informasi yang jelas dari }\end{array}$} \\
\hline & & jawab & & jawab & skor & jawab & & jawab & & \\
\hline 1. & 1 & 2 & 8 & 26 & 78 & 5 & 10 & & & \\
\hline 2. & 2 & - & - & 4 & 12 & 17 & 34 & 13 & 13 & ${ }_{34}$ farmasis mengenai aturan pakai obat ya \\
\hline 3. & 3 & 4 & 16 & 19 & 57 & 10 & & & & 34 diresepkan kepada mereka. Beberapa pasien y \\
\hline 4. & $\frac{4}{5}$ & & 28 & & 66 & $\frac{18}{5}$ & $\frac{36}{11}$ & 16 & 16 & \\
\hline 5. & $\frac{3}{6}$ & $\frac{1}{-}$ & 28 & $\frac{22}{4}$ & $\frac{66}{12}$ & $\frac{5}{21}$ & $\frac{11}{4}$ & $\overline{-}$ & $\overline{9}$ & $\frac{34}{34}$ datang berobat juga secara rutin melakuk \\
\hline 7. & 7 & 1 & 4 & 5 & 15 & 7 & & 21 & 21 & 34 pemeriksaan kesehatan mereka tetapi ada ju \\
\hline 8. & 8 & - & - & 2 & 6 & 17 & 34 & 15 & 15 & 34 yang malas datang melakukan pemerik \\
\hline 9. & 9 & - & - & 3 & 9 & 18 & 36 & 13 & 13 & alas datang melakukan \\
\hline & lah & 14 & 56 & 85 & 255 & 118 & 23 & 89 & 89 & 306 kesehatan rutin. \\
\hline & & 1,5 & 6,2 & 9,4 & 28,3 & 13,1 & 26,2 & 9,8 & 9,8 & \\
\hline
\end{tabular}

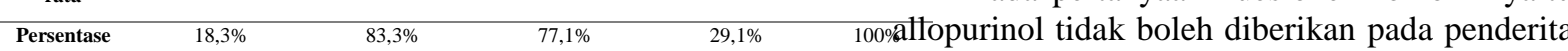
Skor kelainan fungsi ginjal dan pertanyaan nomor 4 yaitu allopurinol untuk mencegah penyerapan pengendapan kalsium oksalat bukan untuk 
penghilang nyeri, 17-18 responden menjawab kurang tahu mengenai hal tersebut disebabkan karena tenaga kesehatan atau farmasis di Klinik Inggit Medical Centre Makassar tidak memberikan PIO (Pelayanan Informasi Obat) yang jelas mengenai hal tersebut dan kurangnya keinginan untuk membaca brosur untuk mendapatkan informasi tentang hal tersebut.

Pada pertanyaan kuesioner mengenai efek samping allopurinol 17-21 responden menjawab kurang tau, bahkan pada pertanyaan kuesioner allopurinol harus dihentikan jika timbul gejala kemerahan pada kulit sebanyak 15 responden menjawab tidak tahu karena kurangnya informasi yang diberikan dari tenaga kesehatan atau farmasis dan kurangnya keinginan pasien untuk langsung bertanya kepada farmasis tentang efek samping obat yang diresepkan.

Dari hasil penelitian juga diperoleh bahwa 19 responden menjawab mengetahui aturan pakai allopurinol di minum satu kali sehari pada malam hari tetapi banyak dari mereka ketika mereka merasakan nyeri langsung meminum obat tersebut dan meminum obat tersebut lagi pada malam hari.

\section{PENUTUP}

\section{A. Kesimpulan}

Berdasarkan hasil penelitian dan pembahasan yang telah diuraikan, maka dapat disimpulkan bahwa pasien yang datang berobat di Klinik Inggit Medical Centre Makassar mulai pada bulan Agustus-September 2020 tahu tentang aturan pakai allopurinol yang telah di resepkan oleh dokter, hal ini dapat dilihat dari persentase skor jawaban responden sebesar 83,3\% (Tabel IV) dimana jumlah persen menunjukkan bahwa pasien yang datang berobat tahu mengenai aturan pakai allopurinol.

B. Saran

1. Tenaga kesehatan atau farmasis dapat memberikan pelayanan informasi obat yang jelas kepada pasien mengenai allopurinol tidak boleh diberikan pada penderita kelainan fungsi ginjal dan untuk mencegah penyerapan pengendapan kalsium oksalat bukan untuk menghilangkan nyeri.

2. Tenaga kesehatan atau farmasis sangat perlu memberikan informasi mengenai efek samping obat yang diresepkan oleh dokter.

\section{DAFTAR PUSTAKA}

Champe Pamela C, 2013. Farmakologi Ulasan Bergambar edisi IV, Ahli bahasa: Adhy Tjahyanto. Penerbit Buku Kedokteran EGC; Jakarta.

Departemen Farmakologi dan Terapeutik FKUI, 2012. Farmakologi dan Terapi edisi V. Balai Penerbit FKUI; Jakarta.

Kasim Fauzi. 2016. Informasi Spesialite Obat (ISO) Indonesia Vol.50. PT ISFI Penerbitan; Jakarta.

Katzung Bertram G, 2002. Farmakologi: Dasar dan Klinik, Ahli Bahasa : Dripa Sjabana, dkk. Salemba Medika; Jakarta.

Kementerian Kesehatan RI, 2014. Peraturan Menteri Kesehatan RI Nomor 9 Tahun 2014 tentang Klinik; Jakarta.

Maesaroh, Siti, 2013. Faktor-Faktor yang Berhubungan dengan Kepatuhan Berobat Pasien Tuberkulosis Paru di Klinik Jakarta Respiratory. Jakarta: Skripsi FKIK Universitas Islam Negeri.

Noer Sjaifoellah, 1996. Buku Ajar Ilmu Penyakit Dalam Jild I edisi III. Balai Penerbit FKUI; Jakarta.

Saputra Lyndon, 2013. Intisari Ilmu Penyakit Dalam. Binarupa Aksara Publisher; Tanggerang.

Sudoyo Aru W, dkk, 2009. Buku Ajar Ilmu Penyakit Dalam Jild III edisi V. InternaPublishing; Jakarta.

Syamsuni, 2006. Farmasetika Dasar dan Hitungan Farmasi. Penerbit Buku Kedokteran EGC; Jakarta.

Ulfa, Maria, 2015. Hubungan Dukungan Keluarga dengan Kepatuhan Minum Obat pada Pasien Tuberkulosis di Wilayah Kerja Puskesmas Pamulang Kota Tangerang Selatan. Jakarta: Skripsi FKIK Universitas Islam Negeri. 